\title{
Editorial
}

\section{Our destination and our destiny: Real endoscopic cardiac surgery}

\author{
W. Randolph Chitwood, Jr, MD
}

See related article on page 776 .

From the Division of Cardiothoracic and Vascular Surgery, East Carolina University, Greenville, NC.

Received for publication May 31, 2006; accepted for publication June 7, 2006.

Address for reprints: W. Randolph Chitwood, Jr, MD, Professor and Chief, Division of Cardiothoracic and Vascular Surgery, East Carolina University, Greenville, NC 27858 (chitwoodw@ecu.edu).

J Thorac Cardiovasc Surg 2006;132:753-4

$0022-5223 / \$ 32.00$

Copyright (C) 2006 by The American Association for Thoracic Surgery

doi:10.1016/j.jtcvs.2006.06.009

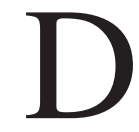
uring the past 10 years, cardiac surgeons have attempted to optimize safety and operative quality while minimizing patient trauma. The springboard for minimizing incision size and altering surgical techniques has been the fact that arterial obstructions could be treated via a single arterial puncture and a catheter. Recently, cardiologists foisted the notion that not only is this approach the least invasive method possible but also that drug-eluting stents are achieving "nirvana" status in curing coronary disease. Similarly, many are convinced that valvular heart disease can be cured or "well" palliated by percutaneous methods that include stent-mounted aortic valves as well as mitral leaflet "clipping" or annular "stiffening" devices. The rise of these and other technologic "wonders" is causing cardiac surgeons to re-evaluate our specialty position in the treatment of cardiovascular diseases. We must now look toward innovative endoscopic methods for doing some cardiac operations.

Our long-standing interest in living physiology and pathology, our direct access to cardiac maladies, and our 50 years of experience in following results of curative rather than palliative cardiac operations have given cardiac surgeons the most experience in treating valve disease. These comments are rendered not to discourage nor denigrate the magnificent technologic advances made by our cardiology colleagues, because they inspired us to change in many ways. However, there is a message and a clarion call for us to develop the least invasive valve operations possible.

What am I saying? In this volume of the Journal, Murphy and associates ${ }^{1}$ describe what they call an endoscopic robotic mitral valve operation. Their clinical results in 127 patients are excellent, despite a reasonably high conversion rate to a sternotomy (4.7\%) and a short follow-up that is incumbent with any new technology. A closed-chest totally endoscopic mitral repair is the goal that many of us have attempted to achieve well before the advent of robotic devices. ${ }^{2}$ The evolution of robotic mitral repair has been relatively slow because the Food and Drug Administration trials were completed in 2001 and the device was approved for intracardiac use in 2002. ${ }^{3}$ Our group has achieved similar results to Murphy's group in over 270 robotic mitral repairs, albeit with no conversions. ${ }^{4}$ Thus, their confirmation of the method's safety and efficacy certainly helps to show that surgeons who develop a team approach and are dedicated to the technique can deliver the least invasive method for mitral repairs. It is clear from our work and Murphy's article that the destination should be truly endoscopic operations, as long as they fulfill the parameters of quality and safety and can be done by multiple surgeons. As cardiac surgeons, our destiny will be determined by our willingness and ability to embrace devices and methods that, heretofore, we never considered.

I envision that the ideal robotic mitral repair would be done endoscopically and completely from the operative console, the reason being that a port incision less than 
$4 \mathrm{~cm}$ does not facilitate extracorporeal knot tying or other cardiac manipulation. These operations are not simply extirpative or ablative but fine valve reconstructions. Thus, it seems incumbent that we perfect methods to reconstruct the mitral valve using only 3-dimensional endoscopic vision and telemanipulation via the tiniest incisions or ports. Murphy and colleagues describe their method of tying repair and atrial closure sutures by a patient-side surgeon assistant. I believe that true endoscopic robotic operations should include making the left atriotomy and establishing retraction, as well as completing valve reconstructions and replacements with associated knot tying, deairing, and atrial closure done from the operating console. This editorial is no criticism of the surgical methods described in this article but is to encourage surgeons who have become interested in using new technology, such as robotic telemanipulation, to try to become asymptotic to the "least invasive operation." Thus, methods shown by Murphy's group and my group certainly are not the destination for minimally invasive mitral surgery. As a specialty, our destiny resides in our interest and ability in melding the fantastic experiences over the past 50 years with developing systems of closed chest visualization, tissue telemanipulation, and operative simulation. Perhaps some day we will even be able to repair mitral valves inside the beating heart using robotics with echocardiographic guidance. The work that is presented in this issue of the Journal is merely a stop on the trip and not the final destination.

\section{References}

1. Murphy DA, Miller JS, Langford DA, Snyder AB, Endoscopic robotic mitral valve surgery, J Thorac Cardiovasc Surg, 2006;132:776-81

2. Chitwood WR Jr, Elbeery JR, Chapman WH, Moran JM, Lust RL, Wooden WA, et al., Video-assisted minimally invasive mitral valve surgery: the "micro-mitral" operation. J Thorac Cardiovasc Surg, 1997; 113:413-4

3. Nifong LW, Chitwood WR, Pappas PS, Smith CR, Argenziano M, Starnes VA, et al. Robotic mitral valve surgery: a United States multicenter trial. J Thorac Cardiovasc Surg, 2005;129:1395-404.

4. Nifong LW, B L, Reade CC, Chitwood WR. 200 Consecutive robotic mitral valve repairs. Circulation, 2005;112(17 pt II):496.

\section{ON THE MOVE?}

Don't miss a single issue of the journal! To ensure prompt service when you change your address, please photocopy and complete the form below.

Please send your change of address notification at least six weeks before your move to ensure continued service. We regret we cannot guarantee replacement of issues missed due to late notification.

\section{JOURNAL TITLE:}

Fill in the title of the journal here.

\section{OLD ADDRESS:}

Affix the address label from a recent issue of the journal here.

\section{NEW ADDRESS:}

Clearly print your new address here.

Name

Address

City/State/ZIP

\section{COPY AND MAIL THIS FORM TO:}

Elsevier Inc.

Subscription Customer Service

6277 Sea Harbor Dr

Orlando, FL 32887
OR FAX TO:

407-363-9661

OR E-mail:

elspcs@elsevier.com
OR PHONE:

800-654-2452

Outside the U.S., call

407-345-4000 